\title{
Understanding Liquidity and Credit Risks in the Financial Crisis*
}

\author{
Deborah Gefang \\ Department of Economics \\ University of Lancaster \\ email: d.gefang@lancaster.ac.uk \\ Gary Koop \\ Department of Economics \\ University of Strathclyde \\ email: Gary.Koop@strath.ac.uk \\ Simon M. Potter \\ Research and Statistics Group \\ Federal Reserve Bank of New York \\ email: simon.potter@ny.frb.org
}

May 2011

\begin{abstract}
This paper develops a structured dynamic factor model for the spreads between London Interbank Offered Rate (LIBOR) and overnight index swap (OIS) rates for a panel of banks. Our model involves latent factors which reflect liquidity and credit risk. Our empirical results show that surges in the short term LIBOR-OIS spreads during the 2007-2009 financial crisis were largely driven by liquidity risk. However, credit risk played a more significant role in the longer term (twelve-month) LIBOR-OIS spread. The liquidity risk factors are more volatile than the credit risk factor. Most of the familiar events in the financial crisis are linked more to movements in liquidity risk than credit risk.
\end{abstract}

${ }^{*}$ The views expressed in this paper are those of the authors and do not necessarily reflect the views of the Federal Reserve Bank of New York or the Federal Reserve System. Gary Koop is a Fellow of the Rimini Center for Economic Analysis. 


\section{Introduction}

One of the most obvious signs of the financial crisis was a jump in the rates on uncollateralized loans across banks in Europe and the US. A standard measure of the rates on these uncollateralized loans is the daily submission of borrowing rates by major banks to the British Bankers Association used to form the standard set of London Interbank Offer Rates (LIBOR). LIBOR rates are referenced in a large number of financial contracts in the global economy. There are three main reasons why LIBOR rates can change: i) central banks can change expectations of their policy rate, thereby repricing most short-term loans between banks; ii) banks can require a higher compensation for default risk on loans and iii) liquidity in the inter-bank loan market can change in ways unrelated to the open market operations of central banks. The last two of these reasons are called credit risk and liquidity risk. In order to focus on the roles of credit and liquidity risks, it is common to take out market expectations of future central bank policy rates by subtracting the overnight index swap (OIS) ${ }^{1}$ rate from the LIBOR rate, leading to the LIBOR-OIS spread. A number of studies emphasize that the LIBOROIS spread contains credit risk and liquidity risk premia (e.g., McAndrews et al, 2008, Michaud and Upper, 2008, Sengupta and Tam, 2008 and Hui et al, 2010). ${ }^{2}$ Detailed chronicles of the sharp increases in LIBOR-OIS spread along with the unfolding of financial turmoil can be found in Sengupta and Tam (2008), Brunnermeier (2009), Thornton (2009) and many other papers.

Disentangling and understanding the relative roles of credit and liquidity risk is of importance to policymakers, in particular during the recent financial crisis. If liquidity risk is the predominant factor, then measures to increase liquidity or improve the functioning of financial markets are desirable policy responses. However, if credit risk predominates, then such measures could be ineffective and policies which influence the solvency of banks are called for.

\footnotetext{
${ }^{1}$ The OIS rate is a commonly-used measure of investor expectations of the effective federal funds rate and should not reflect credit or liquidity risk (see, e.g., Sengupta and Tam, 2008).

${ }^{2}$ According to the Basel Committee on Banking Supervision (2000, 2001), credit risk mostly reflects the uncertainty that a bank borrower or counterparty will fail to repay the loan according to the agreed terms. However, credit risk also arises from various banking activities other than loans, including in the banking book and in the trading book, and both on and off the balance sheet. Liquidity risk arises from banks' potential inability to fund increases in assets and meet obligations when they come due.
} 
The LIBOR-OIS spread has attracted a lot of attention in the literature on the financial crisis. For instance, McAndrews et al (2008), Taylor and Williams (2008a, 2008b) and Wu (2008) investigate whether the Federal Reserve's Term Auction Facility (TAF) has helped to reduce the liquidity risk component embodied in the LIBOR-OIS spread. However, the credit risk and liquidity risk components are rarely explicitly disentangled in the literature (a prominent exception to this statement is Schwarz (2010), a paper which will be discussed below). For example, researchers testing the TAF effect on liquidity premium typically look into the impact of TAF on the LIBOR-OIS spread after including an observed measure, such as the credit default swap (CDS) rate, to control for the credit premium. As noted in McAndrews et al (2008), this practice risks underestimating the TAF effect if liquidity and credit risk premiums is positively correlated. Furthermore, most of the literature has used a single aggregate LIBOR-OIS time series, not exploiting the cross-bank, cross-term and cross-currency variation in LIBOR rates.

In the present paper, we develop an econometric model which exploits these extra dimensions of variation in LIBOR and CDS rates and explicitly includes separate latent variables to model credit and liquidity risks. The main goal is to obtain a better understanding of the evolution of credit and liquidity risks during the financial crisis and investigate the importance of "Good" and "Bad" states for these risks.

Our data includes LIBOR-OIS spreads in the USD (US Dollar), EUR (Euro) and GBP (UK Pound Sterling) markets at different terms for a large panel of banks. Note that the British Bankers Association (BBA) published LIBOR rate (which is used in much of the literature), is calculated based on the trimmed average of the submission rates of all banks listed in the LIBOR panel. In contrast to this, we focus on individual banks' quoted rates. ${ }^{3}$ Submission rates of a bank on a certain LIBOR currency panel are the lowest perceived rates for that bank to get unsecured interbank loans in that currency. Our assumption is that an individual bank's submitted LIBOR rates reflect the bank's own exposure to the latent credit and liquidity risk factors which operate in the market as a whole.

Our empirical results suggest that the widened short term (one-month and three-month) LIBOR-OIS spreads in the financial crisis were largely due to sharp increases in liquidity risks, but the surges in the longer term

\footnotetext{
${ }^{3}$ Information on banks' LIBOR rates submission and how published BBA LIBOR is calculated can be found in the BBA LIBOR Ltd's website http://www.bbalibor.com
} 
(twelve-month) spread were associated with both credit and liquidity risk. Furthermore, the latent liquidity risk factors are found to be much more variable than the credit risk factors and their variation is associated with familiar events in the financial crisis.

The rest of the paper is organized as following. Section 2 presents our modelling framework which section 3 discusses the econometrics. Our Bayesian econometric methods for estimating our models combine standard algorithms, such as Gibbs sampling methods for the dynamic factor and Markov switching models. Accordingly, we do not provide all econometric details in this paper. Instead a Technical Appendix, available on the website

http://personal.strath.ac.uk/gary.koop/, provides complete details of the posterior simulation algorithm along with details of the prior. This appendix also includes additional empirical results including a prior sensitivity analysis and investigation of various identification restrictions and alternative specifications(see Section 4.4 for details). Section 4 describes the empirical results and section 5 concludes.

\section{The Modelling Framework}

Let $S_{i j k t}$ be the spread between an individual bank's $(j=1, \ldots, J$ will denote banks) quoted LIBOR rate at term $i$ (for $i=1, \ldots, I$ ) and the OIS rate of the same term in currency $k$ (for $k=1, \ldots, K$ ) at date $t$ (for $t=1, \ldots, T$ ). This spread is assumed to depend on latent variables measuring liquidity and credit risks which reflect the state of the market as a whole. Liquidity risk is allowed to vary across currencies (since liquidity risk in different currencies will be influenced by country-specific effects and actions of local central banks), but credit risk does not. Thus, let $L_{k t}$ denote liquidity risk in currency $k$ and $C_{t}$ denote the counterparty credit risk amongst banks. $L_{k t}$ and $C_{t}$ are unobserved factors that we are seeking to estimate. To try and disentangle liquidity and credit risk, we model the LIBOR-OIS spread jointly with a second dependent variable which is the CDS rate of an individual bank, $D_{j t}$. The main part of our model can be written as:

$$
\begin{gathered}
S_{i j k t}=\lambda_{i j k}^{S} L_{k t}+\psi_{i j}^{S} C_{t}+\varepsilon_{i j k t}^{S} \\
D_{j t}=\psi_{j}^{C} C_{t}+\gamma^{\prime} Z_{t}+\varepsilon_{j t}^{D}
\end{gathered}
$$


where $Z_{t}$ is an observed explanatory variable, $\varepsilon_{i j k t}^{S} \sim \operatorname{IIDN}\left(0, \sigma_{i j k S}^{2}\right), \varepsilon_{j t}^{D} \sim$ $\operatorname{IIDN}\left(0, \sigma_{j D}^{2}\right)$ and these errors are independent of each other.

Note that this model embodies many assumptions which allow us to identify the liquidity and credit risks. Most importantly, the CDS rate of a bank is assumed not to depend directly on the liquidity risk in the market as a whole. ${ }^{4}$ Next, note the subscripts on the factor loadings. These vary across terms, to capture the effect that, in the financial crisis, banks were especially reluctant to lend to each other at longer maturities. They also vary across banks. However, the credit risk factor has an impact of the LIBOR-OIS spread which is the same across currencies. Given our previous interpretation of the credit risk factor as it impacts upon global banks, we argue the latter assumption is sensible.

Dynamic factor models such as ours require identification restrictions. The previous assumptions partially identify the model. In this paper, we impose the following restrictions on factor loadings in order to uniquely identify and interpret the factors:

$$
\begin{array}{cc}
\lambda_{i j k}^{S}>0, & \lambda_{11 k}^{S}=1 \\
\psi_{j}^{C}>0, & \psi_{1}^{C}=1 \\
\psi_{i j}^{S}>0, & \psi_{11}^{S}=1
\end{array}
$$

These are standard identifying restrictions of the sort commonly used in the factor model literature. They have no substantive implications for the interpretation of results. For instance, the inequality restrictions above ensure that increases in $L_{k t}$ and $C_{t}$ increase the LIBOR-OIS spread and the CDS rate (i.e. high values of these latent variables indicate a bad liquidity/credit risk situations). Setting $\lambda_{11 k}^{S}=\psi_{1}^{C}=\psi_{11}^{S}=1$ is a standard was of ensuring identification in dynamic factor models such as ours. ${ }^{5}$

\footnotetext{
${ }^{4}$ This assumption, along with the assumption that there is a single latent credit risk variable common to all banks (albeit with bank-specific factor loadings), is different from the approach of Schwarz (2010). In our Technical Appendix, we also present results for the following specification:

$$
S_{i j k t}=\lambda_{i j k}^{S} L_{k t}+\psi_{i j k}^{S} D_{j t}+\varepsilon_{i j k t}^{S}
$$

which does not involve these assumptions.

${ }^{5}$ Our identification scheme normalizes the factor loading for the term $i=1$ to unity. We experimented with normalizing on $i=2$ or 3 and results were virtually unaltered. Details are given in our Technical Appendix.
} 
To complete the dynamic factor model, we have to specify equations describing the evolution of $L_{k t}$ and $C_{t}$. We assume they evolve over time according to Markov-switching $\mathrm{AR}(1)$ processes. The AR choice allows for us to model persistence in the states, but the Markov-switching allows for the abrupt switches which may have occurred in the financial crisis. Formally, we allow the latent factors, $C_{t}$ and $L_{k t}$, to depend on Markov-switching states, $s_{t}^{C} \in\left\{G_{C}, B_{C}\right\}$ and $s_{t}^{L} \in\left\{G_{L}, B_{L}\right\}$, where our $G$ and $B$ notation indicates "good" and "bad" states for credit and liquidity risks:

$$
\begin{gathered}
L_{k t}=\phi_{k 0}^{L}\left(s_{t}^{L}\right)+\phi_{k 1}^{L}\left(s_{t}^{L}\right) L_{k, t-1}+\sigma_{k L}\left(s_{t}^{L}\right) v_{k t}^{L}, \\
C_{t}=\phi_{0}^{C}\left(s_{t}^{C}\right)+\phi_{1}^{C}\left(s_{t}^{C}\right) C_{t-1}+\sigma_{C}\left(s_{t}^{C}\right) v_{t}^{C},
\end{gathered}
$$

where $v_{k t}^{L}$ and $v_{t}^{C}$ are independent standard Normal (i.e. independent over time and of each other). To ensure stationarity of the dynamics of the linear factors, we impose the restrictions:

$$
\begin{gathered}
0 \leq \phi_{1}^{C}\left(s_{t}^{C}\right)<1 \\
0 \leq \phi_{1}^{L}\left(s_{t}^{L}\right)<1 .
\end{gathered}
$$

With regards to the Markov switching part of the model, note that there are four possible combinations of the good and bad credit and liquidity states. Thus, we can define $s_{t}$ as

$$
s_{t} \in\left\{\left(G_{L}, G_{C}\right),\left(B_{L}, G_{C}\right),\left(G_{L}, B_{C}\right),\left(B_{L}, B_{C}\right)\right\} .
$$

For instance, $\left(B_{L}, B_{C}\right)$ is when the bad state rules in both credit and liquidity markets which can be interpreted as the financial crisis state. The transition probabilities for the four-state Markov-switching process can be expressed through the $4 \times 4$ matrix $M$ :

$$
\left\{\begin{array}{llll}
m_{11} & m_{12} & m_{13} & m_{14} \\
m_{21} & m_{22} & m_{23} & m_{24} \\
m_{31} & m_{32} & m_{33} & m_{34} \\
m_{41} & m_{42} & m_{43} & m_{44}
\end{array}\right\}
$$

where $\iota_{4}^{\prime} M=\iota_{4}^{\prime}$, with $\iota_{4}=[1,1,1,1]^{\prime}$ ensures that probabilities sum to one. To ensure that $G$ and $B$ represent good and bad states we restrict the unconditional means of $C_{t}$ and $L_{k t}$ to be lower in the good states than in the bad:

$$
\frac{\phi_{0}^{C}\left(G_{C}\right)}{1-\phi_{1}^{C}\left(G_{C}\right)}<\frac{\phi_{0}^{C}\left(B_{C}\right)}{1-\phi_{1}^{C}\left(B_{C}\right)}
$$




$$
\begin{aligned}
\frac{\phi_{0}^{L}\left(G_{L}\right)}{1-\phi_{1}^{L}\left(G_{L}\right)} & <\frac{\phi_{0}^{L}\left(B_{L}\right)}{1-\phi_{1}^{L}\left(B_{L}\right)} \\
E\left[\sigma_{C}\left(G_{C}\right)\right] & <E\left[\sigma_{C}\left(B_{C}\right)\right] \\
E\left[\sigma_{k L}\left(G_{L}\right)\right] & <E\left[\sigma_{k L}\left(B_{L}\right)\right]
\end{aligned}
$$

That is, spreads and credit risk are higher and more volatile on average in the bad states.

Note that the liquidity factors across currencies are linked through this Markov state, since we assume the same $s_{t}$ holds for all currencies. Thus, it captures the inter-linked nature of liquidity. However, by having different coefficients for different currencies (e.g. $\phi_{k 1}^{L}\left(s_{t}^{L}\right)$ and other parameters differ across currencies), we allow for the impacts of differences in monetary policy implementation and provision of central bank liquidity.

\section{Bayesian Estimation Methods}

Bayesian estimation of our model can be done using a Markov Chain Monte Carlo (MCMC) algorithm which combines familiar algorithms for dynamic factor and Markov switching models. Accordingly, we do not provide details here, but provide only a sketch of how the algorithm proceeds. A Technical Appendix containing full details of our MCMC algorithm is available on http://personal.strath.ac.uk/gary.koop/. Our model depends on the latent credit and liquidity risk factors $\left(L_{k t}\right.$ and $\left.C_{t}\right)$, and the Markov switching states $\left(s_{t}^{L}\right.$ and $\left.s_{t}^{C}\right)$. Conditional on all these latent variables, the model defined by (1), (2), (3) and (4) is a multivariate Normal linear regression model and our MCMC algorithm can draw on standard methods to draw the factor loadings and other parameters of the model. Conditional on draws of these parameters and draws of $s_{t}^{L}$ and $s_{t}^{C}$, standard methods for drawing factors can be used to draw $L_{k t}$ and $C_{t}$. We use the algorithm described in Kim and Nelson (1999, chapter 8).

Conditional on draws of $L_{k t}$ and $C_{t}$ and the parameters in (1), (2), (3) and (4), we use methods for drawing from Markov switching models described in Kim and Nelson (1999, chapter 9).

Our prior imposes the inequality and equality restrictions on the parameters described in the previous section, but is otherwise relatively noninformative. Precise details are provided in the Technical Appendix to this paper. We have carried out an extensive prior sensitivity analysis which shows our 
results are robust, even to reasonably large changes in the prior. Results of this prior sensitivity analysis are also available in the Technical Appendix.

We use the posterior expectation of the Bayesian information criterion (BIC) and Akaike's information criterion (AIC) to compare models.

\section{Empirical Results}

\subsection{Data}

Our daily data runs from 2 January 2007 to 15 December 2009 for the following 12 banks (acronyms used in tables in parentheses) that listed in the LIBOR panels for USD, GBP and EUR: Barclays (barclays), Bank of TokyoMitsubishi UFJ (btmufj), Citibank (citibank), Deutsche Bank (deutschebank), JPMorgan Chase (jpmc), HBOS (hbos), HSBC (hsbc), Lloyds TSB Bank (lloyds), Rabobank (rabobank), Royal Bank of Scotland (rboscotland), UBS (ubs), and WestLB (westlb). For each bank, we consider three term rates: one-month, three-month and twelve-month.

We use the implied volatility of overall stock prices (VIX) for $Z_{t}$ in equation(2). Note that $D_{j t}$ is a measure of bank-specific credit risk and inclusion of the VIX controls for volatility in the market as a whole (e.g. Hakkio and Keeton, 2009). Both LIBOR-OIS spread and CDS rate are measured in basis points, while VIX is a percentage. To have all the data of approximately the same magnitude, we divide both CDS and VIX data by 100 and demean all the variables. Excluding common holidays and weekends, ${ }^{6}$ we have 727 observations for each variable.

\subsection{Model Comparison}

In addition to the very flexible unrestricted model described in Section 2, we estimate several restricted models which reduce the number of latent liquidity factors and/or remove the Markov switching part of the model. Altogether, we estimated eight models:

- Model A (the Full Model): One latent credit risk factor, three latent liquidity risk factors in USD, GBP and EUR, respectively.

\footnotetext{
${ }^{6}$ Four of the banks have a small number of missing observations. We omit these observations for these banks.
} 
- Model B: One latent credit risk factor, one common latent liquidity risk factor in USD and GBP, one unique latent liquidity risk factor in EUR.

- Model C: One latent credit risk factor, one unique latent liquidity risk factor in USD, one common latent liquidity risk factor in GBP and EUR.

- Model D: One latent credit risk factor, one common latent liquidity risk factor in USD, GBP and EUR.

- Model E: Same as Model A but without Markov switching.

- Model F: Same as Model B but without Markov switching.

- Model G: Same as Model C but without Markov switching.

- Model H: Same as Model D but without Markov switching. ${ }^{7}$

Before presenting empirical results relating to financially-relevant features of interest, it is important to present statistical information on which models are supported by the data. Table 1 reports AIC and BIC for these eight models. The first point that stands out is that neither of the information criteria vary by a large amount across models. If we were to do a Bayesian model averaging exercise using the information criteria to construct model weights, then all of the models would receive appreciable probability. Secondly, Models A (the full unrestricted model) and E (which is the same as Model A except removes the Markov switching component of the model) are the two models which perform best according to both information criteria. AIC chooses the Model A as being best whereas the more parsimonious BIC chooses Model E.

Both Model A and Model E include three liquidity risk factors, one for each of the currency markets (USD, EUR, GBP). Note that Table 1 indicates little support for the idea that it is statistically acceptable to reduce the number of liquidity risk factors. Models with a single liquidity risk factor perform worst in Table 1. Models with two liquidity risks factors, one for the USD and the second for the EUR and GBP, do not perform too poorly,

\footnotetext{
${ }^{7}$ We also consider four models same as Models A to D but with only two-state Markovswitching. As these models are not favored either by AIC or BIC, for brevity, we relegate the empirical results to the Technical Appendix.
} 
but are clearly out-performed by models with three liquidity risk factors. Thus, statistically-speaking, we are finding evidence to support our practice of using information in the three currency markets, as opposed to working solely with the USD market (as it typically done in the literature).

\begin{tabular}{|l|l|l|}
\hline \multicolumn{3}{|c|}{ Table 1: Model Comparison } \\
\hline & BIC & AIC \\
\hline Model A & -3.171 & -4.231 \\
\hline Model B & -2.783 & -3.824 \\
\hline Model C & -2.915 & -3.956 \\
\hline Model D & -2.513 & -3.536 \\
\hline Model E & -3.185 & -4.195 \\
\hline Model F & -2.790 & -3.794 \\
\hline Model G & -2.959 & -3.963 \\
\hline Model H & -2.525 & -3.522 \\
\hline
\end{tabular}

\subsection{Financial Features of Interest}

\subsubsection{The Factors}

In light of the findings of the preceding sub-section, in our discussion of financial features of interest, we will restrict our attention to the Full Model (Model A) and the Best Model (Model E) selected by BIC.

There are many financially-interesting features of interest in our modelling framework. In addition to the parameters in the model, we can present the latent factors, $L_{k t}$ and $C_{t}$, which shed light on liquidity and credit risk. For the Full Model, we can also present the probabilities of our four states (i.e. $\left.\left\{\left(G_{L}, G_{C}\right),\left(B_{L}, G_{C}\right),\left(G_{L}, B_{C}\right),\left(B_{L}, B_{C}\right)\right\}\right)$ relating to the Markov switching aspect of the model

Furthermore, to investigate the relative roles of credit and liquidity risks in the financial crisis, we also present a variance decomposition based on the LIBOR-OIS equations. As explained in McAndrews et al (2008), credit and liquidity risks might be correlated. The existence of possibly correlated components renders variance decomposition a less straightforward exercise. From (1), we have the following:

$$
\begin{aligned}
\operatorname{var}\left(S_{i j k t}\right)= & \left(\lambda_{i j k}^{S}\right)^{2} \operatorname{var}\left(L_{k t}\right)+\left(\psi_{i j}^{S}\right)^{2} \operatorname{var}\left(C_{t}\right)+\operatorname{var}\left(\varepsilon_{i j k t}^{S}\right) \\
& +2 \lambda_{i j k}^{S} \psi_{i j}^{S} \operatorname{cov}\left(L_{k t}, C_{t}\right) .
\end{aligned}
$$


Following, e.g., Campbell and Ammer (1993), we report all the components on the right hand side of equation (5) as a proportion of $\operatorname{var}\left(S_{i j k t}\right)$. This decomposition will allow us to see the the relevant importance of the different terms on the right hand side of (1).

The posterior mean of the latent credit and liquidity risks are presented in Figure 1 (for the Full Model) and Figure 2 (for the Best Model). ${ }^{8}$ Figure 1 and Figure 2 exhibit almost identical patterns, indicating that the addition of Markov switching states adds little to our understanding of credit and liquidity risk. The three liquidity risk factors tend to move together (although there are some important differences between them which we will note below) in a manner that is quite different from the credit risk factor.

First let us consider credit risk. This tended to grow gradually from August 2007 to a peak in December 2008, before gradually decreasing. By the end of 2009, credit risk was still at a level higher than in August 2007, the time when the financial turmoil first emerged. However, it is interesting to note the two clear dips in credit risk before December 2008. The first happened in December 2007. This was around the time when many banks were forced to take additional large write downs. Furthermore, the Fed's term auction facility (TAF) first opened on December 17, 2007 (although the dip in Figures 1 and 2 began well before December 17). It seems that immediate response in the market to these events was that the perceived credit risk dropped, though this drop only lasted for the month of December 2007 and by January 2008 credit risk returned to where it had been before the dip began. The second smaller drop (or a plateau in the gradual increase) in credit risk happened in the summer of 2008. However, by late summer of 2008, the gradual increase in credit risk resumed (even before Lehman Brothers finally went bankrupt in September 2008 and AIG disclosed that it faced serious liquidity shortage). It worth mentioning that credit risk remained at a high level throughout 2009, only slightly lower than its December 2008 peak. But it is worth stressing that the movements in the latent credit risk tend to be gradual and there is no huge spike in credit risk in autumn 2008.

In contrast to the credit risk, liquidity risks rose and dropped more abruptly. Figures 1 and 2 show that there were three major upsurges in liquidity risk, with by far the largest being at the time when the financial crisis was at its worst (i.e. in autumn 2008). The other two peaks in liquidity risk occurs in August 2007 and December 2007. August 2007 is often cited as

\footnotetext{
${ }^{8}$ To aid visual inspection, we normalize each risk factor by its own standard deviation.
} 
the beginning of the financial crisis when Northern Rock's problems became clear. Also in August, central banks implemented a wide range of unprecedented liquidity easing approaches. For instance, European Central Bank (ECB) injected 95 billion Euros in overnight credit and the Fed injected $\$ 24$ billion. Our methodology is finding all liquidity risks to have dropped after an August 2007 peak, although this drop was much more rapid in the USD than the EUR market. The second peak, in early to mid-December 2007 is just before the time that the Fed's term auction facility, TAF, began. It first opened on December 17, 2007 and our methodology is finding liquidity risk to have fallen shortly after this.

During all of these upsurges, liquidity risks in the three different currencies behaved broadly similarly to one another. However, there are many minor differences in their behavior (which presumably accounts for why models with fewer than three liquidity factors performed poorly in Table 1). One notable difference is that the EUR liquidity risk exhibited a fourth upsurge in May and June 2008 which does not appear in the USD and GBP liquidity risks. Furthermore, as noted above, after the August 2007 increase in liquidity risk (common to all currencies), liquidity risk remained high in the EUR market well after it declined in the other currencies.

Another interesting difference between currencies can be noted at the time that the credit crunch was at its worst. In October 2008, when all the three liquidity risks skyrocketed, liquidity risk in USD led those of the other currencies (and especially the GBP). Furthermore, the USD liquidity risk reached a higher level than the EUR liquidity risk. Interestingly, after reaching the peak, liquidity risks in USD and EUR dropped much more rapidly than those in the GBP currency market.

As noted above, the comparison between the evolution of credit risk and the liquidity risks is quite informative. Credit risk tends to move quite slowly, whereas we have seen liquidity risks swayed up and down more rapidly and in a manner consistent with the familiar events of the financial crisis. This suggests the importance of liquidity risk relative to credit risk in the evolution of the financial crisis. We will investigate this point in greater depth below. 


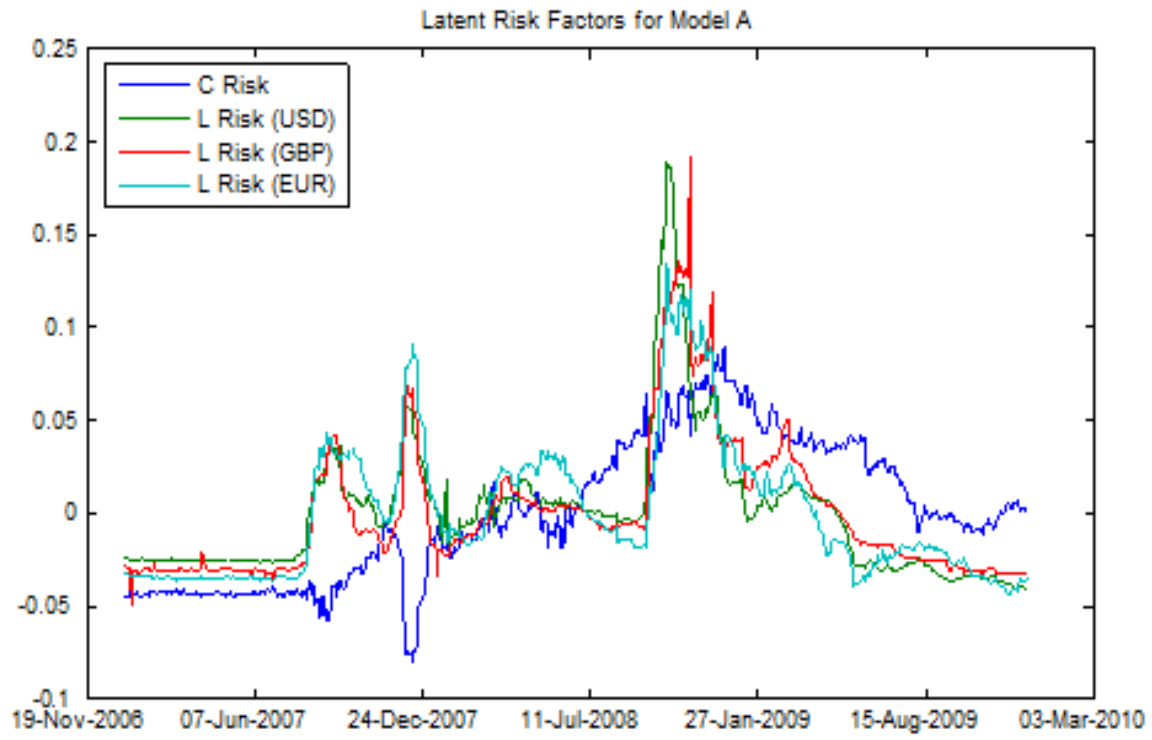

Figure 1 


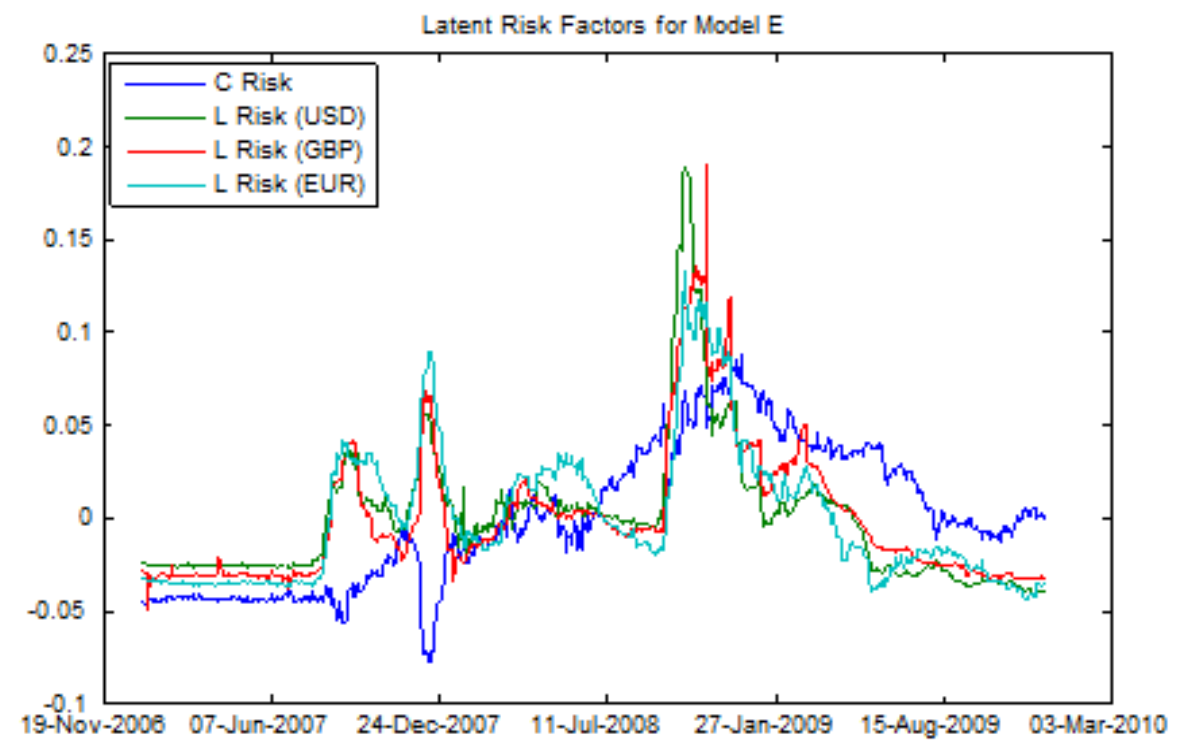

Figure 2

\subsubsection{The Markov Switching States}

Table 1 and the similarity of the results in Figures 1 and 2 suggest that our 4 state Markov switching specification is difficult to distinguish from a constant parameter latent factor model (the technical appendix contains results for a two state model). It seems that gradual evolution of factors, as state equations such as (3) and (4) would allow for (even if we removed the Markov switching state variable), is adequate to capture the salient features of the dynamics in the data we use in this study. Nevertheless, our Full Model which includes the Markov switching does receive appreciable support in Table 1, so it is worthwhile to briefly present empirical results relating to this aspect of the model.

Table 2 presents information about the posterior of the matrix of transition probabilities. We find that $90 \%$ of the time the model is either in the $\left(G_{L}, G_{C}\right)$ or $\left(B_{L}, B_{C}\right)$ state. This accounts for why the probabilities for remaining in the other states are quite low and imprecisely estimated (as revealed by large posterior standard deviations). The point estimates imply that the good credit and good liquidity state is quite persistent (i.e. given 
it is currently in this state, the probability of remaining in it is 95\%). The bad liquidity and bad credit state is somewhat less persistent (i.e. the point estimate tells us the probability of remaining there is $73 \%$ ).

\begin{tabular}{|c|c|c|c|c|}
\hline \multicolumn{5}{|c|}{$\begin{array}{c}\text { Table 2: Posterior Mean of Transition Probabilities } \\
\text { (Posterior standard deviations in parentheses) }\end{array}$} \\
\hline & $\left(G_{L}, G_{C}\right)$ & $\left(B_{L}, G_{C}\right)$ & $\left(G_{L}, B_{C}\right)$ & $\left(B_{L}, B_{C}\right)$ \\
\hline \multirow{2}{*}{$\left(G_{L}, G_{C}\right)$} & 0.9454 & 0.2675 & 0.1765 & 0.1056 \\
& $(0.0132)$ & $(0.1511)$ & $(0.1085)$ & $(0.0526)$ \\
\hline \multirow{2}{*}{$\left(B_{L}, G_{C}\right)$} & 0.0135 & 0.2572 & 0.0746 & 0.1033 \\
& $(0.0086)$ & $(0.1513)$ & $(0.0686)$ & $(0.0746)$ \\
\hline \multirow{2}{*}{$\left(G_{L}, B_{C}\right)$} & 0.0155 & 0.0875 & 0.6446 & 0.0640 \\
& $(0.0106)$ & $(0.0828)$ & $(0.1577)$ & $(0.0437)$ \\
\hline \multirow{2}{*}{$\left(B_{L}, B_{C}\right)$} & 0.0256 & 0.3878 & 0.1043 & 0.7271 \\
& $(0.0113)$ & $(0.1859)$ & $(0.0905)$ & $(0.0861)$ \\
\hline
\end{tabular}

Figures 3 through 6 plot posterior means of the states themselves for the four states. Figures 3 and 6 are of most interest since, as just discussed, the states plotted in Figures 4 and 5 (i.e. $\left(B_{L}, G_{C}\right)$ and $\left.\left(G_{L}, B_{C}\right)\right)$ rarely occur in our data set. Given this fact, Figures 3 and 6 can be seen (approximately) to be mirror images of each other. Our main findings are that, at the heart of the credit crunch (from mid-September through mid-November 2008), the bad liquidity and bad credit state holds (with a few exceptions). The other periods when the bad liquidity and credit state often has high probability are similar to periods discussed previously and associated with the liquidity risk upsurges noted in Figures 1 and 2. These are late August through midSeptember, 2007 and December 2007.

Thus, Table 2 and Figures 3 through 6 indicate that the major periods of the credit crisis were associated with increases in both credit and liquidity risk. 


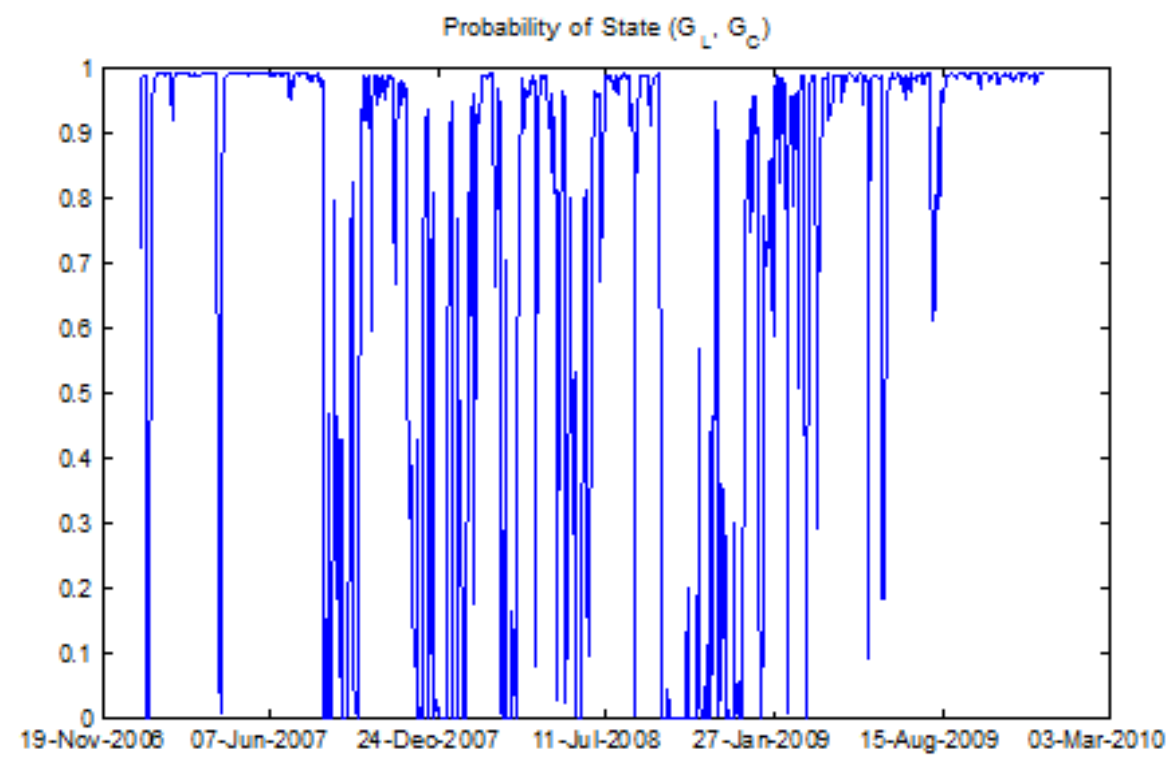

Figure 3 




Figure 4 


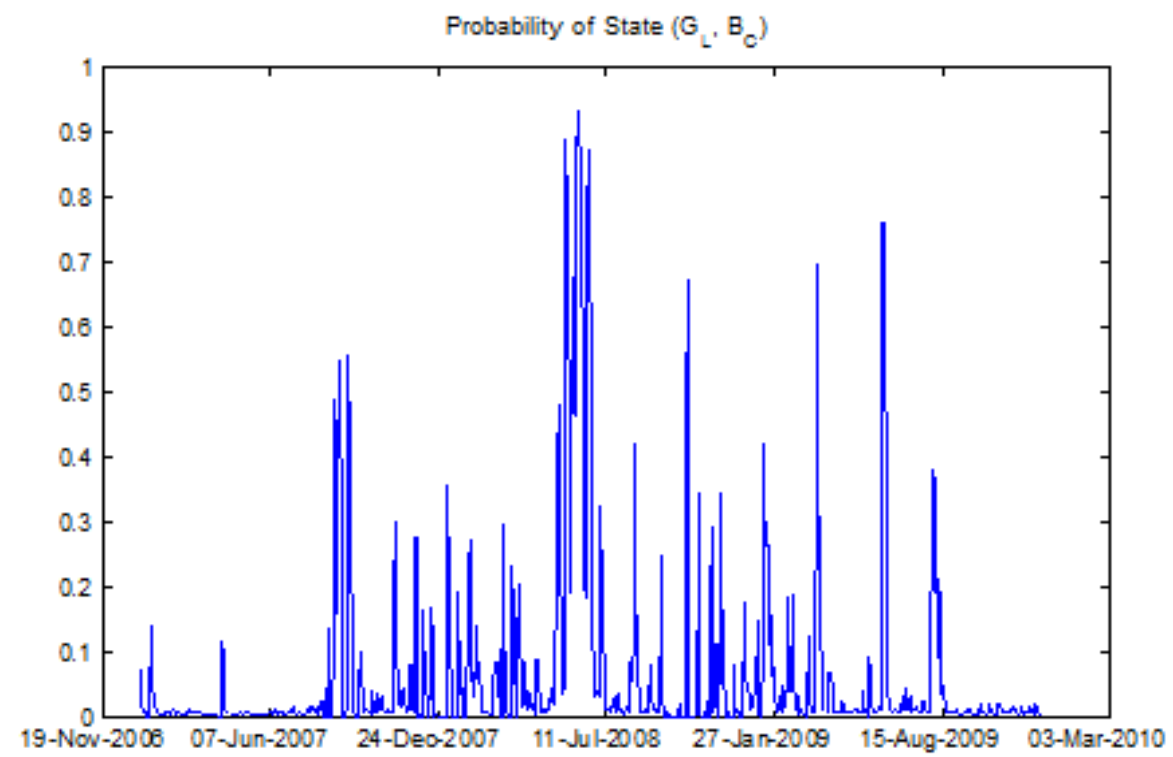

Figure 5 


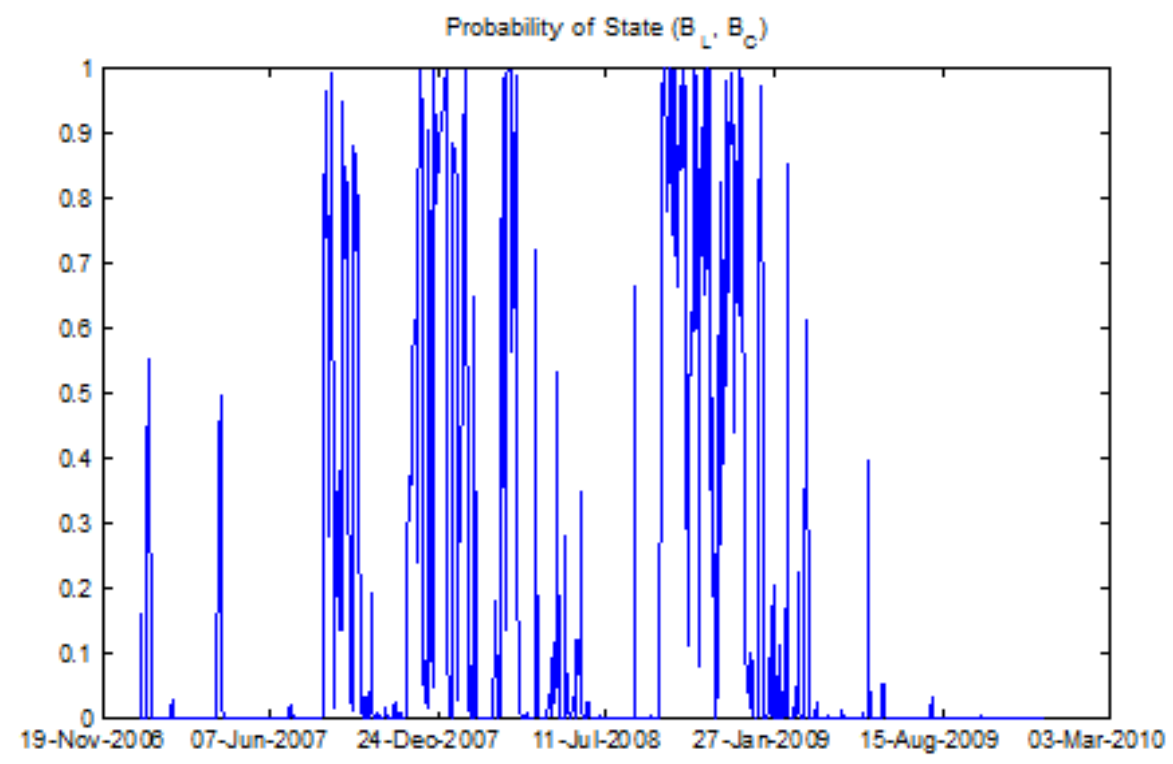

Figure 6

\subsubsection{Variance Decompositions}

Our results thus far suggest that both liquidity and credit risk played a role in the financial crisis, although the former played a more important role than the latter. The variance decomposition of (5) can be used to formalize these findings. Noting that this decomposition relates to $\operatorname{var}\left(S_{i j k t}\right)$, it follows that we will have a variance decomposition for each bank, term and currency (i.e. each $i, j$ and $k$ ). These are presented in Tables 3, 4 and 5 for the Full Model. Results using the Best Model are similar and will not reported here for the sake of brevity.

Note first that results in these tables indicate our model is fitting well, with the error rarely accounting for more than $10 \%$ of the variation in spreads and typically accounting for much less (especially at the 3 month term). Furthermore, there are substantive differences across banks, terms and currencies which provides us with strong evidence of the need for studies such as the present one which exploits these panel dimensions in the econometric model.

The pattern in the tables is for liquidity risk to play the predominant role at short terms (1 month or 3 months). Particularly for one month LIBOR- 
OIS spreads, we have strong evidence that liquidity risk has been the major driver. For the GBP, the proportion of the variability in one month spreads attributable to the liquidity risk factor is typically very near to one (e.g. numbers like 0.99 or 0.98 are common) and never less than 0.80 . For the USD and EUR markets the role of liquidity risk, although still high, is somewhat lower (e.g. numbers like 0.89 and 0.90 are common). ${ }^{9}$

At the three month term, a similar pattern holds but the role of liquidity risk is somewhat less than at the one month term. But there are important differences across currencies. That is, in the USD markets, liquidity risk typically accounts for 75 or $80 \%$ of the variability in spreads. But in the GBP market these numbers tend to be around $65 \%$ and in the EUR markets even lower than this.

At the 12 month term, however, a different picture emerges. At this longer term, credit risk assumes a much more important role. Although there is some variation across currencies and over banks, we are tending to find credit risk to account for about $50 \%$ of the variability in spreads in the USD markets (results for the GBP are slightly lower and EUR slightly higher than this). Liquidity risk is still important, tending to account for 20 or $30 \%$ of the variability in spreads in the USD markets (with results for the GBP being slightly higher and EUR slightly lower than this). However, credit risk is clearly the more important factor at this longer term in the vast majority of cases.

The role of the covariance between the liquidity and credit risk factors tends to be fairly small, accounting for typically around $10 \%$ of the variability in spreads. The other covariance terms in the variance decomposition play a negligible role.

Note that the main dependent variable in our study is $S_{i j k t}$, as opposed to most of the related literature which works with $S_{t}$. The preceding discussion of the variance decompositions (as well as our earlier empirical results) have shown that there are substantive differences across currencies and terms, emphasizing the importance of having $i k$ subscripts on our dependent variable. But what about the $j$ subscript? Are there benefits from working with a panel of banks, as we do, rather than just working with an aggregate LIBOR-OIS

\footnotetext{
${ }^{9}$ There have been concerns that several banks manipulated LIBOR rates during the financial crisis (see, among many others, Abrantes-Metz, Kraten, Metz and Seow, 2008). The existence and degree of such manipulation is hotly debated in the literature, but if banks were under-reporting LIBOR rates then this would have a tendency to lead to underestimates of liquidity risk in our model.
} 
spread which averages over banks? With one exception, an examination of Tables 3 to 5 indicates that, although there is some variation across banks, it is not as large as the variation across term and currency area with the exception of one bank HBOS. The role of the credit risk factor for HBOS, at all terms and in all currencies, consistently is very low. Especially at longer horizons it is much lower than the other banks in the sample.

\subsection{Robustness to Modelling Assumptions}

In this paper, we have presented results using a very flexible model and compared the full model to several restricted versions of it. We have used a proper, but relatively noninformative prior and a sensible identification scheme. We have investigated other modelling assumptions and have found our results to be very robust. Since these investigations do not substantively alter the empirical conclusions of this paper (and for the sake of brevity), we do not present these additional empirical results here. Instead they are included in the Technical Appendix to this paper available at http://personal.strath.ac.uk/gary.koop/.

In particular, this appendix contains results from a prior sensitivity analysis and different identification assumptions. The different identifying assumptions are described in footnote 7 (i.e. normalizing the factor loading matrices in different ways) and footnote 5 (i.e. relaxing the assumption that there is a single latent credit risk variable by simply including $D_{j t}$ as an explanatory variable in the spread equations). The appendix also contains results from a specification where there are two states in the Markov switching part of the model, instead of four. Empirical results are similar in all of these specification to those presented above.

Furthermore, we also estimated the model using data of the eight banks for which we do not have any missing observations. These are barclays, citibank, deutschebank, jpmc, lloyds, rabobank, rboscotland, ubs. The latent risk factors derived from the eight bank panel are found to be very similar to what we get from the twelve bank panel. 


\begin{tabular}{|c|c|c|c|c|}
\hline & $\operatorname{var}(\mathrm{L})$ & $\operatorname{var}(\mathrm{C})$ & $\operatorname{cov}(\mathrm{L}, \mathrm{C})$ & $\operatorname{var}(\mathrm{e})$ \\
\hline barclays $_{1 m}$ & 0.8920 & 0.0000 & 0.0000 & 0.1080 \\
\hline barclays $_{3 m}$ & 0.8201 & 0.0723 & 0.0968 & 0.0107 \\
\hline barclays $_{12 m}$ & 0.2713 & 0.4223 & 0.1345 & 0.1719 \\
\hline btmufj $j_{1 m}$ & 0.8766 & 0.0042 & 0.0240 & 0.0953 \\
\hline btmufj $j_{3 m}$ & 0.7792 & 0.1031 & 0.1127 & 0.0050 \\
\hline btmuf $j_{12 m}$ & 0.2120 & 0.5353 & 0.1339 & 0.1188 \\
\hline citibank $_{1 m}$ & 0.8990 & 0.0015 & 0.0148 & 0.0847 \\
\hline citibank $_{3 m}$ & 0.7706 & 0.1105 & 0.1160 & 0.0029 \\
\hline citibank $_{12 m}$ & 0.1982 & 0.5595 & 0.1323 & 0.1100 \\
\hline deutschebank $k_{1 m}$ & 0.9122 & 0.0000 & 0.0003 & 0.0875 \\
\hline deutschebank $k_{3 m}$ & 0.7868 & 0.0986 & 0.1108 & 0.0039 \\
\hline deutschebank $k_{12 m}$ & 0.2902 & 0.4677 & 0.1464 & 0.0957 \\
\hline$h_{b o s_{1 m}}$ & 0.8696 & 0.0000 & 0.0002 & 0.1302 \\
\hline$h b o s_{3 m}$ & 0.8347 & 0.0039 & 0.0223 & 0.1391 \\
\hline$h_{b o s_{12 m}}$ & 0.6065 & 0.0499 & 0.0690 & 0.2746 \\
\hline$h s b c_{1 m}$ & 0.9112 & 0.0001 & 0.0029 & 0.0859 \\
\hline$h s b c_{3 m}$ & 0.7868 & 0.0995 & 0.1113 & 0.0024 \\
\hline$h s b c_{12 m}$ & 0.2654 & 0.4848 & 0.1426 & 0.1072 \\
\hline$j p m c_{1 m}$ & 0.9040 & 0.0000 & 0.0002 & 0.0958 \\
\hline$j p m c_{3 m}$ & 0.7682 & 0.1080 & 0.1146 & 0.0092 \\
\hline$j p m c_{12 m}$ & 0.1845 & 0.5488 & 0.1264 & 0.1403 \\
\hline lloyds $s_{1 m}$ & 0.9213 & 0.0000 & 0.0006 & 0.0782 \\
\hline lloyds $s_{3 m}$ & 0.7707 & 0.1108 & 0.1162 & 0.0024 \\
\hline lloyds $s_{12 m}$ & 0.1896 & 0.5630 & 0.1298 & 0.1175 \\
\hline rabobank $_{1 m}$ & 0.9025 & 0.0006 & 0.0090 & 0.0880 \\
\hline rabobank $_{3 m}$ & 0.7452 & 0.1241 & 0.1209 & 0.0098 \\
\hline rabobank $_{12 m}$ & 0.2103 & 0.5232 & 0.1318 & 0.1347 \\
\hline rboscotland $_{1 m}$ & 0.9195 & 0.0001 & 0.0036 & 0.0768 \\
\hline rboscotland $_{3 m}$ & 0.7678 & 0.1102 & 0.1157 & 0.0063 \\
\hline rboscotland $_{12 m}$ & 0.1860 & 0.5165 & 0.1232 & 0.1743 \\
\hline$u b s_{1 m}$ & 0.9175 & 0.0002 & 0.0046 & 0.0778 \\
\hline$u b s_{3 m}$ & 0.7550 & 0.1221 & 0.1208 & 0.0021 \\
\hline$u b s_{12 m}$ & 0.1922 & 0.5360 & 0.1275 & 0.1443 \\
\hline westlb $_{1 m}$ & 0.8729 & 0.0015 & 0.0145 & 0.1110 \\
\hline westlb $_{3 m}$ & 0.7360 & 0.1312 & 0.1236 & 0.0093 \\
\hline westlb $_{12 m}$ & 0.1811 & 0.5567 & 0.1262 & 0.1360 \\
\hline
\end{tabular}




\begin{tabular}{|c|c|c|c|c|}
\hline & $\operatorname{var}(\mathrm{L})$ & $\operatorname{var}(\mathrm{C})$ & $\operatorname{cov}(\mathrm{L}, \mathrm{C})$ & $\operatorname{var}(\mathrm{e})$ \\
\hline barclays $_{1 m}$ & 0.9964 & 0.0000 & 0.0000 & 0.0036 \\
\hline barclays $_{3 m}$ & 0.6928 & 0.1121 & 0.1497 & 0.0454 \\
\hline barclays $_{12 m}$ & 0.3386 & 0.4230 & 0.2032 & 0.0353 \\
\hline btmufj $j_{1 m}$ & 0.9361 & 0.0081 & 0.0467 & 0.0091 \\
\hline btmuf $j_{3 m}$ & 0.6625 & 0.1302 & 0.1577 & 0.0497 \\
\hline btmuf $j_{12 m}$ & 0.4036 & 0.3838 & 0.2113 & 0.0013 \\
\hline citibank $_{1 m}$ & 0.9625 & 0.0026 & 0.0266 & 0.0084 \\
\hline citibank $_{3 m}$ & 0.6607 & 0.1208 & 0.1517 & 0.0668 \\
\hline citibank $_{12 m}$ & 0.3853 & 0.4010 & 0.2111 & 0.0027 \\
\hline deutschebank $k_{1 m}$ & 0.9892 & 0.0000 & 0.0005 & 0.0103 \\
\hline deutschebank $_{3 m}$ & 0.6802 & 0.1199 & 0.1534 & 0.0465 \\
\hline deutschebank $k_{12 m}$ & 0.4656 & 0.3149 & 0.2056 & 0.0138 \\
\hline$h b o s_{1 m}$ & 0.8167 & 0.0000 & 0.0003 & 0.1829 \\
\hline$h b o s_{3 m}$ & 0.6712 & 0.0047 & 0.0297 & 0.2944 \\
\hline$h_{b o s_{12 m}}$ & 0.5562 & 0.0369 & 0.0767 & 0.3301 \\
\hline$h s b c_{1 m}$ & 0.9705 & 0.0002 & 0.0058 & 0.0236 \\
\hline$h s b c_{3 m}$ & 0.6553 & 0.1310 & 0.1573 & 0.0564 \\
\hline$h s b c_{12 m}$ & 0.4217 & 0.3603 & 0.2093 & 0.0087 \\
\hline$j p m c_{1 m}$ & 0.9898 & 0.0000 & 0.0003 & 0.0099 \\
\hline$j p m c_{3 m}$ & 0.6913 & 0.1081 & 0.1468 & 0.0538 \\
\hline$j p m c_{12 m}$ & 0.4490 & 0.3369 & 0.2089 & 0.0052 \\
\hline lloyds $s_{1 m}$ & 0.9978 & 0.0000 & 0.0010 & 0.0012 \\
\hline lloyds $_{3 m}$ & 0.6784 & 0.1212 & 0.1540 & 0.0465 \\
\hline lloyds $s_{12 m}$ & 0.3861 & 0.4016 & 0.2114 & 0.0010 \\
\hline rabobank $_{1 m}$ & 0.9700 & 0.0008 & 0.0151 & 0.0141 \\
\hline rabobank $_{3 m}$ & 0.6677 & 0.1210 & 0.1526 & 0.0587 \\
\hline rabobank $_{12 m}$ & 0.4463 & 0.3361 & 0.2080 & 0.0096 \\
\hline rboscotland $_{1 m}$ & 0.9906 & 0.0002 & 0.0069 & 0.0023 \\
\hline rboscotland $_{3 m}$ & 0.6549 & 0.1371 & 0.1609 & 0.0472 \\
\hline rboscotland $_{12 m}$ & 0.3497 & 0.4346 & 0.2093 & 0.0064 \\
\hline$u b s_{1 m}$ & 0.9859 & 0.0003 & 0.0086 & 0.0052 \\
\hline$u b s_{3 m}$ & 0.6403 & 0.1416 & 0.1617 & 0.0564 \\
\hline$u b s_{12 m}$ & 0.4006 & 0.3869 & 0.2114 & 0.0011 \\
\hline westlb $_{1 m}$ & 0.9663 & 0.0026 & 0.0267 & 0.0044 \\
\hline westlb $_{3 m}$ & 0.6492 & 0.1464 & 0.1656 & 0.0388 \\
\hline westlb $_{12 m}$ & 0.3910 & 0.3964 & 0.2114 & 0.0011 \\
\hline
\end{tabular}




\begin{tabular}{|c|c|c|c|c|}
\hline & $\operatorname{var}(\mathrm{L})$ & $\operatorname{var}(\mathrm{C})$ & $\operatorname{cov}(\mathrm{L}, \mathrm{C})$ & $\operatorname{var}(\mathrm{e})$ \\
\hline barclays $_{1 m}$ & 0.8950 & 0.0000 & 0.0000 & 0.1050 \\
\hline barclays $_{3 m}$ & 0.6512 & 0.1994 & 0.1392 & 0.0101 \\
\hline barclays $_{12 m}$ & 0.2178 & 0.5947 & 0.1390 & 0.0485 \\
\hline btmuf $j_{1 m}$ & 0.8506 & 0.0155 & 0.0442 & 0.0897 \\
\hline btmuf $j_{3 m}$ & 0.6106 & 0.2399 & 0.1479 & 0.0015 \\
\hline btmuf $j_{12 m}$ & 0.2302 & 0.5811 & 0.1413 & 0.0474 \\
\hline citibank $_{1 m}$ & 0.8570 & 0.0046 & 0.0241 & 0.1143 \\
\hline citibank $_{3 m}$ & 0.6320 & 0.2215 & 0.1446 & 0.0020 \\
\hline citibank $_{12 m}$ & 0.2282 & 0.5792 & 0.1404 & 0.0522 \\
\hline deutschebank $k_{1 m}$ & 0.8598 & 0.0000 & 0.0005 & 0.1397 \\
\hline deutschebank $_{3 m}$ & 0.5904 & 0.2386 & 0.1450 & 0.0260 \\
\hline deutschebank $k_{12 m}$ & 0.2779 & 0.5379 & 0.1494 & 0.0348 \\
\hline$h b o s_{1 m}$ & 0.8275 & 0.0000 & 0.0003 & 0.1721 \\
\hline$h b o s_{3 m}$ & 0.7504 & 0.0078 & 0.0293 & 0.2125 \\
\hline$h_{b o s_{12 m}}$ & 0.5567 & 0.0615 & 0.0713 & 0.3105 \\
\hline$h s b c_{1 m}$ & 0.8614 & 0.0003 & 0.0051 & 0.1332 \\
\hline$h s b c_{3 m}$ & 0.6450 & 0.2086 & 0.1417 & 0.0047 \\
\hline$h s b c_{12 m}$ & 0.2903 & 0.5176 & 0.1498 & 0.0423 \\
\hline$j p m c_{1 m}$ & 0.9017 & 0.0000 & 0.0003 & 0.0980 \\
\hline$j p m c_{3 m}$ & 0.6554 & 0.2020 & 0.1406 & 0.0020 \\
\hline$j p m c_{12 m}$ & 0.2781 & 0.5288 & 0.1481 & 0.0450 \\
\hline lloyds $s_{1 m}$ & 0.8916 & 0.0000 & 0.0009 & 0.1075 \\
\hline lloyds $s_{3 m}$ & 0.6301 & 0.2228 & 0.1448 & 0.0024 \\
\hline lloyds $s_{12 m}$ & 0.2032 & 0.6021 & 0.1351 & 0.0596 \\
\hline rabobank $_{1 m}$ & 0.8812 & 0.0015 & 0.0139 & 0.1034 \\
\hline rabobank $_{3 m}$ & 0.6036 & 0.2308 & 0.1442 & 0.0214 \\
\hline rabobank $_{12 m}$ & 0.2730 & 0.5330 & 0.1473 & 0.0467 \\
\hline rboscotland $_{1 m}$ & 0.8770 & 0.0003 & 0.0061 & 0.1166 \\
\hline rboscotland $_{3 m}$ & 0.6101 & 0.2356 & 0.1465 & 0.0078 \\
\hline rboscotland $_{12 m}$ & 0.1843 & 0.6220 & 0.1307 & 0.0630 \\
\hline$u b s_{1 m}$ & 0.8350 & 0.0005 & 0.0079 & 0.1566 \\
\hline$u b s_{3 m}$ & 0.5823 & 0.2586 & 0.1499 & 0.0091 \\
\hline$u b s_{12 m}$ & 0.2273 & 0.5866 & 0.1410 & 0.0451 \\
\hline westlb $_{1 m}$ & 0.8536 & 0.0044 & 0.0235 & 0.1186 \\
\hline westlb $_{3 m}$ & 0.5921 & 0.2526 & 0.1494 & 0.0059 \\
\hline westlb $_{12 m}$ & 0.2332 & 0.5842 & 0.1426 & 0.0400 \\
\hline
\end{tabular}




\subsection{Further Discussion of Empirical Results}

We have presented evidence in favor of our econometric methods, shown the robustness of the results they provide and found that working with individual bank data (as opposed to aggregates) is important. Broadly speaking we are finding evidence of the importance of liquidity considerations during the financial crisis, particularly at short terms. When we compare our results to those of one of the few other papers which seeks to disentangle liquidity and credit risks, we find that a great deal of similarity. In particular, our findings our consistent with those of Schwarz (2010), which concludes that market liquidity considerations accounted for more than two-thirds of the changes in one-month and three-month LIBOR-OIS spreads. Schwarz (2010) differs from our approach in that the author uses additional data sources to directly obtain estimates of liquidity. That is, data on German government guaranteed bonds (i.e. with no credit risk) of varying liquidity are used to obtain measures of market liquidity. This contrasts with our approach where risk is treated as a latent factor which is not directly observed. Nevertheless, it is useful to see two differing approaches yielding similar results.

We should strike a note of caution, however, when interpreting our results. There have been concerns that several banks manipulated LIBOR rates during the financial crisis (see, among many others, Abrantes-Metz, Kraten, Metz and Seow, 2008). The existence and degree of such manipulation is hotly debated in the literature. And, by using data at the bank level, and allowing for bank-specific factor loadings, our results may not be greatly effected by a small amount of manipulation in a small number of banks. Furthermore, if banks were under-reporting LIBOR rates then this would cave a tendency to lead to underestimates of liquidity risk in our model. Nevertheless, the possibility of manipulation in these markets should be noted.

Furthermore, in other asset markets, the importance of explicitly modelling term spreads has been emphasized (see, e.g., Piazzesi and Swanson, 2008). Note, however, that our equation for the latent liquidity risk variable has an intercept in it. And this intercept has a coefficient which can vary across terms, thus accommodating such term spread effects.

Finally, the policy importance of our results should be emphasized. In the introduction to this paper, we stressed that the policy implications of a credit crunch are quite different than a liquidity crunch. Our empirical results suggest the importance of liquidity factors in the financial crisis. 


\section{Conclusion}

In this paper, we have motivated and developed a statistical model which uses a panel of LIBOR-OIS spreads and bank CDS rates to disentangle liquidity and credit risk. The panel dimensions of the spreads include variation across banks, currencies and terms. The existing literature almost always ignores these panel dimensions and simply works with one average LIBOROIS spread. From a statistical point of view, our empirical results show that there are benefits from exploiting these panel dimensions in terms of increasing our understanding of liquidity and credit risk.

Our empirical results indicate that liquidity and credit risks both played an important role in the financial crisis. However, especially at the 1 month and 3 month terms, the role of liquidity risks is much more important. At the 12 month term, credit and liquidity risks both play an important role. The latent liquidity risk factors are much more variable than the credit risk factor and their variation is associated with familiar events in the financial crisis. 


\section{References}

Abrantes-Metz, R., Kraten, M., Metz, A., Seow, G., 2008. Libor manipulation?, working paper available at SSRN http://papers.ssrn.com/sol3/papers.cfm?abstract_id=12

Basel Committee on Banking Supervision, 2000, Sound practices for managing liquidity in banking organisations, consultative document available at http://www.bis.org/publ/bcbs69.pdf.

Basel Committee on Banking Supervision, 2001, The new Basel capital accord, consultative document available at http://www.bis.org/publ/bcbsca03.pdf.

Brunnermeier, M., 2009. Deciphering the liquidity and credit crunch 2007-2008. Journal of Economic Perspectives. 23, 77-100.

Campbell, J., Ammer, J., 1993. What moves the stock and bond markets? A variance decomposition for long-term asset returns. Journal of Finance. $48,3-37$.

Hakkio, C., Keeton, W., 2009. Financial stress: What is it, how can it be measured, and why does it matter? Federal Reserve Bank of Kansas City Economic Review. Third Quarter, 5-50.

Hui, C., Chang, T., Lo, C., 2010. Using interest rate derivative prices to estimate LIBOR-OIS spread dynamics and systemic funding liquidity shock probabilities. Hong Kong Monetary Authority, working paper 04/2010.

Kim, C. and Nelson, C., 1999. State Space Models with Regime Switching. MIT Press, Cambridge, MA.

McAndrews, J., Sarkar, A., Wang, Z., 2008. The effect of the term auction facility on the London inter-bank offered rate. Federal Reserve Bank of New York Staff Report No. 335.

Michaud, F., Upper, C., 2008. What drives interest rates? Evidence from the Libor panel. BIS Quarterly Review, March, 47-58.

Piazzesi, M., Swanson, E., 2008. Futures prices as risk-adjusted forecasts of monetary policy. Journal of Monetary Economics. 55, 677-691.

Schwarz, K., 2010. Mind the gap: Disentangling credit and liquidity in risk spreads, working paper available at SSRN: http://ssrn.com/abstract $=1486240$.

Sengupta, R., Tam Y., 2008. The LIBOR-OIS spread as a summary indicator. Monetary Trends, Federal Reserve Bank of St. Louis, Nov. 25.

Taylor, J., and Williams, J., 2008a. A black swan in the money market. Working Paper, Stanford University and the Federal Reserve Bank of San Francisco 2008-4.

Taylor, J., and Williams, J., 2008b. Further results on a black swan in the money market, Stanford Institute for Economic Policy Research Working Paper 07-046. 
Thornton, D., 2009. What the Libor-OIS spread says, Economic Synopses, Federal Reserve Bank of St. Louis.

Wu, T., 2008. On the effectiveness of the Federal Reserve's new liquidity facilities, Federal Reserve Bank of Dallas, Working Paper 0808. 